\title{
CRESCIMENTO IN VITRO DE FUNGOS (Colletotrichum gloeosporioides e Cladosporium cladosporioides) ISOLADOS DE FRUTOS DO MAMOEIRO, SOB ATMOSFERA CONTROLADA E REFRIGERAÇÃO ${ }^{1}$
}

\author{
DANIELA GOUVEIA VIEIRA², ROBERTA MANHÃES DA SILVA², OTNIEL FREITAS SILVA ${ }^{3}$, \\ MARCOS JOSÉ DE OLIVEIRA FONSECA ${ }^{3}$, ANTÔNIO GOMES SOARES ${ }^{3}$, ROBERTO ALEXANDRE COSTA ${ }^{4}$
}

\begin{abstract}
RESUMO - O uso combinado das tecnologias de atmosfera controlada e de refrigeração, em frutas tropicais, não apresenta ainda resultados satisfatórios, talvez pela suscetibilidade à injúria por frio, agravada nas condições de controle atmosférico. Como há indícios de que a atmosfera controlada tem efeito fungistático, este trabalho foi elaborado para se verificar, in vitro, sua influência sobre dois fungos fitopatogênicos do mamão: Colletotrichum gloeosporioides e Cladosporium cladosporioides, sob refrigeração. Colônias destes fungos foram submetidas a duas temperaturas de armazenamento $\left(10\right.$ e $\left.25^{\circ} \mathrm{C}\right)$, a duas atmosferas (ambiente e controlada com $3 \% \mathrm{O}_{2}$ e $\left.6 \% \mathrm{CO}_{2}\right)$ e por dois períodos $(7$ ou 14 dias). Após este armazenamento, as placas foram incubadas a $25^{\circ} \mathrm{C}$ sob atmosfera ambiente, por mais sete dias. Foi verificado menor crescimento da colônia de Colletotrichum gloeosporioides sob refrigeração, em relação ao armazenamento a $25^{\circ} \mathrm{C}$, inclusive após o período adicional a $25^{\circ} \mathrm{C}$, independentemente da atmosfera de armazenamento. Não se verificou efeito inibitório significativo da atmosfera controlada a $10^{\circ} \mathrm{C}$, sobre o crescimento de Colletotrichum gloeosporioides. O crescimento deste fungo somente foi reduzido quando armazenado sob atmosfera controlada a $25^{\circ} \mathrm{C}$, em relação ao armazenamento em atmosfera normal. O crescimento do fungo Cladosporium cladosporioides foi reduzido a $10^{\circ} \mathrm{C}$, em relação ao armazenamento a $25^{\circ} \mathrm{C}$, em ambos os períodos de armazenamento, independentemente da atmosfera de armazenamento. Após sete dias a $25^{\circ} \mathrm{C}$, o crescimento de Cladosporium cladosporioides foi menor nas placas que foram armazenadas por 14 dias a $10^{\circ} \mathrm{C}$, pela influência da refrigeração e de um possível efeito residual da atmosfera controlada deletério ao crescimento da colônia. A atmosfera controlada reduziu o crescimento da colônia de $C$. cladosporioides, a $25^{\circ} \mathrm{C}$, em relação à atmosfera normal.
\end{abstract}

Termos para indexação: colônia de fungo, atmosfera controlada, Carica papaya, Colletotrichum gloeosporioides, Cladosporium cladosporioides

\section{IN VITRO GROWTH OF Colletotrichum gloeosporioides AND Cladosporium cladospodioides UNDER CONTROLLED ATMOSPHERE AND REFRIGERATION}

\begin{abstract}
The use of these combined technologies in tropical fruits does not present satisfactory results yet, most of the time because of the fruits injury by chilling. This injury could be intensified under atmospheric control conditions. There are evidences that the controlled atmosphere has fungistatic effect. Therefore, the objective of this work was verifying, in vitro, the influence of controlled atmosphere and temperature on the two pathogenic fungi from papaya fruit: Colletotrichum gloeosporioides and Cladosporium cladosporioides. These fungi had been storage under two temperatures, atmospheres and period of incubation patterns $\left(10^{\circ} \mathrm{C}\right.$ and $25^{\circ} \mathrm{C}$; ambient and controlled $-3 \%$ $\mathrm{O}_{2}$ and $6 \% \mathrm{CO}_{2} ; 7$ or 14 days. After this period of storage, the contaminated plates had been incubated at $25^{\circ} \mathrm{C}$ under environment atmosphere for seven days more. It was verified a small growth of Colletotrichum gloeosporioides under refrigeration, also after additional period at $25^{\circ} \mathrm{C}$. At $25^{\circ} \mathrm{C}$, the growth of this fungus was also reduced when stored under controlled atmosphere. On the other hand, it was not verified significant inhibitor effect of the controlled atmosphere at $10^{\circ} \mathrm{C}$ on the growth of C. gloeosporioides. The growth of Cladosporium cladosporioides was reduced at $10^{\circ} \mathrm{C}$ in both periods of storage. After seven days at $25^{\circ} \mathrm{C}, \mathrm{C}$. cladosporioides showed a small growth in the plates that had been stored for 14 days, because the influence of the refrigeration and the controlled atmosphere. Finally, the controlled atmosphere reduced the growth of the C. cladosporioides at $25^{\circ} \mathrm{C}$. This effect was not observed at $10^{\circ} \mathrm{C}$ for $C$. gloeosporioides.
\end{abstract}

Index terms: controlled atmosphere, Carica papaya, Colletotrichum gloeosporioides, Cladosporium cladosporioides

\section{INTRODUÇÃO}

A contaminação fúngica em mamão é uma das causas de perdas pós-colheita e pode ser causada por várias espécies que colonizam os tecidos e causam perdas significativas, destacam-se, entre outros, Colletotrichum gloeosporioides e Cladosporium cladosporioides (Peres et al., 2003). Colletotrichum gloeosporioides é o principal agente causador de perdas em pós-colheita de mamão, seja na forma de podridão peduncular, seja na forma de antracnose na casca, alcançando, até, a polpa do fruto (Nery-Silva, 1999). Cladosporium cladosporioides pode ser isolado do ar, solo, frutas estocadas, grãos, gêneros alimentícios, entre outros. A temperatura ótima para seu crescimento varia de $18^{\circ} \mathrm{C}$ a $28^{\circ} \mathrm{C}$, porém apresenta também bom crescimento entre as temperaturas máximas $28^{\circ} \mathrm{C}-32^{\circ} \mathrm{C}$ e mínima de $-6^{\circ} \mathrm{C}$ (Snowdon, 1991).

A atmosfera controlada (AC) é definida como o armazenamento realizado sob condições de composição da atmosfera conhecida e diferente daquela presente na atmosfera do ar normal
(Lana, 2000). Normalmente, a AC é associada à refrigeração para otimizar seu efeito. Os efeitos das altas concentrações de $\mathrm{CO}_{2}$ e baixas de $\mathrm{O}_{2}$ sobre a respiração e o amadurecimento são aditivos. No entanto, níveis de $\mathrm{CO}_{2}$ acima do limite de tolerância podem causar injúria, e níveis de $\mathrm{O}_{2}$, abaixo do limite de tolerância, podem induzir a respiração anaeróbia. A manutenção de, no mínimo, 1-3\% de $\mathrm{O}_{2}$ é necessária para evitar mudanças de respiração aeróbia para anaeróbia, o que mudaria a rota glicolítica: o ácido pirúvico deixa de ser oxidado, para ser descarboxilado a acetaldeído, $\mathrm{CO}_{2}$ e etanol (Lana, 2000).

Wszelaki e Mitcham (2000) constataram que $15 \mathrm{kPA}$ de $\mathrm{CO}_{2}$, associados ou não a $40 \mathrm{kPa}$ de $\mathrm{O}_{2}$, foi o tratamento que promoveu maior supressão do crescimento de Botrytis cinerea in vitro, após 7 dias. Em todos os tratamentos, o crescimento do fungo aumentou ao se desfazer a condição de atmosfera controlada, indicando não haver efeito residual ou efeito fungicida. Yackel et al. (1971) verificaram sensibilidade diferenciada para 7 fungos causadores de doenças pós-colheita (Penicillium expansum, Aspergillus niger, Mucor hiemalis, Fusarium bulbigenum, Cladosporium herbarum, Rhizopus

${ }_{1}^{1}$ (Trabalho 210-2005). Recebido: 21-12-2005. Aceito para publicação: 20-10-2006.

2 Bolsista CNPq - Av. das Américas, 29.501 - Guaratiba - Rio de Janeiro - RJ - CEP 23020-470.

${ }_{3}^{3}$ Embrapa Agroindústria de Alimentos, Av. das Américas, 29.501 - Guaratiba - Rio de Janeiro - RJ - CEP 23020-470. ofreitas@ctaa.embrapa.br, mfonseca@ctaa.embrapa.br, agomes@ctaa.embrapa.br

${ }^{4}$ Engenheiro Agronomo, MSc, Bolsista da Fundação Oswaldo Cruz, Instituto de Tecnologia em Fármacos - Far-Manguinhos/FIOCRUZ, Departamento de Química de Produtos Naturais, Rio de Janeiro, RJ.; roberto_a_costa@hotmail.com. 
oryzae e Alternaria sp.), mas que esta seria relacionada à temperatura, sendo mais efetiva sob refrigeração e com tendência de redução do crescimento fúngico. O crescimento inicial de Cladosporium herbarum foi reduzido pelo armazenamento sob AC, e esta redução foi maior quanto menor a temperatura. Atualmente, este fungo é denominado Cladosporium cladosporioides. O objetivo do presente estudo foi comparar o crescimento in vitro dos fungos Colletotrichum gloeosporioides e Cladosporium cladosporioides (patógenos na fase de pós-colheita do mamão), durante o armazenamento sob atmosfera controlada, em condições de refrigeração e temperatura ambiente.

\section{MATERIAL E MÉTODOS}

Os experimentos foram realizados nos Laboratórios de Patologia Pós-colheita e Fisiologia Pós-colheita da Embrapa Agroindústria de Alimentos, Rio de Janeiro-RJ.

Na primeira etapa, os fungos Colletotrichum gloeosporioides e Cladosporium cladosporioides foram isolados de mamão infectado e transferidos para placas de Petri $(60$ X $15 \mathrm{~mm})$ descartáveis, contendo meio Dicloran Rose Bengal Cloranfenicol Ágar (Ágar DRBC) e mantidos em câmaras a $25^{\circ} \mathrm{C}$, por sete dias. Após o crescimento dos isolados, foram feitas repicagens consecutivas até a obtenção de culturas puras. Por meio de preparações em lâminas e observações ao microscópio, identificaram-se os organismos baseada em suas características morfológicas. Após o período de incubação de aproximadamente sete dias, discos com micélio de cada fungo (Colletotrichum gloeosporioides e Cladosporium cladosporioides) foram transferidos para placas de Petri de $150 \mathrm{~mm}$ de diâmetro X 15 $\mathrm{mm}$ de altura (sendo um disco para cada placa) contendo Ágar DRBC; a tampa de cada placa foi levemente inclinada, para permitir que a atmosfera programada para cada microcâmara entrasse em contato direto com o fungo inoculado. $\mathrm{O}$ experimento foi montado, nas microcâmaras, em quatro tratamentos: atmosfera ambiente com $\mathrm{pO}_{2}$ de $21 \%$, $\mathrm{pCO}_{2}$ de $0 \%$, a $10^{\circ} \mathrm{C}$; atmosfera ambiente com $\mathrm{pO}_{2}$ de $21 \%$, $\mathrm{pCO}_{2}$ de $0 \%$, a $25^{\circ} \mathrm{C}$; atmosfera controlada com $\mathrm{pO}_{2}$ de $3 \%$ e $\mathrm{pCO}_{2}$ de $6 \%, \mathrm{a} 10^{\circ} \mathrm{Ce} 4$ ) atmosfera controlada com $\mathrm{pO}_{2}$ de $3 \%$ e pCO de $6 \%$, a $25^{\circ} \mathrm{C}$, em 5 replicatas de cada tratamento.

O crescimento radial do patógeno foi estebelecido mediante determinação do diâmetro da colônia, aos 7 e 14 dias. Após a avaliação inicial, as placas foram colocadas mais sete dias em temperatura e atmosfera ambientes, quando seus diâmetros foram novamente medidos, para verificação de algum possível efeito residual sobre o crescimento da colônia.

Foi adotado o delineamento inteiramente casualizado, com 5 replicatas, em esquema fatorial com 2 atmosferas, 2 temperaturas de armazenamento e 4 períodos de armazenamento $(2 \times 2 \times 4)$. Foi realizada análise de variância e utilizado o teste de Tukey, a 5\% de probabilidade.

\section{RESULTADOS E DISCUSSÃO}

As análises de variâncias dos dados obtidos para os fungos Colletotrichum gloeosporioides e Cladosporium cladosporioides revelaram que as interações entre temperaturaXatmosferaXdata de avaliação e atmosferaXdata de avaliação foram não-significativas a $5 \%$ de probabilidade, pelo teste F. Assim, foram estudados para ambos os fungos os efeitos das interações entre atmosferaXtemperatura $(\mathrm{p}<0,01$ e $\mathrm{p}<0,01)$ e temperaturaXdata de avaliação $(\mathrm{p}<0,01$ e $\mathrm{p}<0,05$, respectivamente) (Tabela 1$)$.

\section{Colletotrichum gloeosporioides}

O crescimento da colônia de Colletotrichum gloeosporioides foi menor sob temperatura de armazenamento a $10^{\circ} \mathrm{C}$, durante 7 e 14 dias, em câmara fria (Tabela 2), continuando menor após o período posterior de sete dias, a $25^{\circ} \mathrm{C}$, a que todas as placas foram submetidas, em relação às placas armazenadas a $25^{\circ} \mathrm{C}$. Não houve diferença significativa para o crescimento da colônia de
Colletotrichum gloeosporioides entre os períodos de permanência em câmara fria a $10^{\circ} \mathrm{C}$ ( 7 ou 14 dias), o que comprova a ação efetiva da temperatura na inibição de seu crescimento. Ao expor as placas à temperatura de $25^{\circ} \mathrm{C}$ por período adicional de sete dias, ocorreu intenso e significativo crescimento das colônias. Após 7 dias a $25^{\circ}$ $\mathrm{C}$, não houve diferença significativa do crescimento entre as placas anteriormente armazenadas por 7 ou 14 dias, a $10^{\circ} \mathrm{C}$.

$\mathrm{O}$ crescimento da colônia, sete dias após o armazenamento, foi maior naquelas placas que haviam sido armazenadas previamente por sete dias, em relação àquelas armazenadas por 14 dias, independentemente da atmosfera de armazenamento (Tabela 2). Uma possível explicação é que, naquelas placas armazenadas por 14 dias e submetidas à atmosfera controlada, o crescimento possa ter sido menor. Isto não pode ser visualizado devido à interação temperatura e atmosfera ter sido não-significativa ( $\mathrm{Na}$ Tabela 2, somente são apresentados os dados referentes à interação de temperatura e períodos de avaliação). Assim, após o armazenamento por 14 dias em atmosfera controlada, a $25^{\circ} \mathrm{C}$, o crescimento da colônia de Colletotrichum gloeosporioides pode ter sido inibido pela restrição de oxigênio e aumento da concentração de dióxido de carbono, mesmo expondo-o, posteriormente, à atmosfera normal por sete dias. Nas placas armazenadas por sete dias, o efeito deletério da atmosfera controlada pode não ter sido tão extenso quanto seria por 14 dias. Vale ressaltar que esta especulação sobre o possível efeito da atmosfera controlada somente pode ser válida no armazenamento a $25^{\circ} \mathrm{C}$, temperatura esta que não inibe o crescimento das colônias de C. gloeosporioides.

Seria também esperado que houvesse diâmetro de crescimento absoluto maior nas placas armazenadas por mais tempo (14 dias), em qualquer das temperaturas, seguido de mais 7 dias a $25^{\circ} \mathrm{C}$. A possível explicação para este fato é que o armazenamento sob refrigeração reduziu o crescimento das colônias em maior magnitude, quanto maior for o período de exposição a esta condição de armazenamento.

Houve diferença significativa no crescimento das colônias de C. gloeosporioides, sob atmosfera ambiente e atmosfera controlada, a $25^{\circ} \mathrm{C}$, ou seja, a atmosfera controlada, por si só, foi efetiva na inibição dos fungos que permaneceram nas câmaras, a $25^{\circ} \mathrm{C}$. O mesmo não foi observado a $10^{\circ} \mathrm{C}$, indicando que o controle atmosférico não é eficiente sob armazenamento refrigerado (Tabela 3). O crescimento das colônias foi, estatisticamente, reduzido sob refrigeração, em ambas as atmosferas de conservação.

\section{Cladosporium cladosporioides}

Não houve diferença significativa para o crescimento das colônias de Cladosporium cladosporioides, entre os períodos de permanência (7 ou 14 dias) na câmara fria a $10^{\circ} \mathrm{C}$. No entanto, observou-se maior crescimento nas placas armazenadas por 14 dias, a $25^{\circ} \mathrm{C}$, em relação ao período de sete dias (Tabela 4), evidenciando que a refrigeração, por si só, inibiria parcialmente o crescimento das colônias do fungo Cladosporium cladosporioides.

O diâmetro das colônias de C. cladosporioides foi maior naquelas placas que haviam permanecido mais tempo sob refrigeração $\left(14\right.$ dias a $10^{\circ} \mathrm{C}$ ), após 7 dias, a $25^{\circ} \mathrm{C}$ (Tabela 4). Por outro lado, foi observado resultado inverso em armazenamento a $25^{\circ} \mathrm{C}$. Após período adicional de sete dias, a $25^{\circ} \mathrm{C}$, houve maior crescimento das colônias de C. cladosporioides armazenado por sete dias, a $25^{\circ}$ $\mathrm{C}$, em relação a 14 dias. A contradição encontrada, possivelmente, pode ser atribuída à influência da atmosfera controlada sobre o fungo, durante o período de armazenamento (7 ou 14 dias). No caso do armazenamento a $10^{\circ} \mathrm{C}$, a atmosfera controlada não teria efeito sobre o crescimento micelial, devido à restrição ao crescimento imposto pela refrigeração. Assim, após a remoção da refrigeração, o fungo armazenado em qualquer período de tempo teria condições de crescer em temperatura normal. Entretanto, ao se armazenar o fungo a $25^{\circ} \mathrm{C}$, a atmosfera ambiente influenciaria no crescimento da colônia, restringindo seu desenvolvimento posterior quanto maior fosse seu período de armazenamento, sob atmosfera controlada. 
Houve menor crescimento das colônias que permaneceram a $10^{\circ} \mathrm{C}$, quando comparado com a temperatura de $25^{\circ} \mathrm{C}$, durante sete e 14 dias. Ao expor o fungo a $25^{\circ} \mathrm{C}$, por mais 7 dias, observaram-se resultados contraditórios em função da extensão do período prévio de refrigeração. Naquelas placas que haviam permanecido por 7 dias a $10^{\circ} \mathrm{C}$, após 7 dias a $25^{\circ} \mathrm{C}$ (Tabela 4 ), o crescimento manteve-se menor. Contraditoriamente, foi verificado maior crescimento da colônia a $10^{\circ} \mathrm{C}$, por 14 dias, após 7 dias a $25^{\circ} \mathrm{C}$, em relação àquelas armazenadas pelos mesmos 14 dias a $25^{\circ} \mathrm{C}$ (Tabela 4).

Os diâmetros das colônias foram maiores a $25^{\circ} \mathrm{C}$, em ambas as atmosferas de armazenamento (Tabela 5), confirmando que a refrigeração reduz o crescimento fúngico. Não houve diferença para crescimento micelial na temperatura de $10^{\circ} \mathrm{C}$, no que diz respeito à ação das atmosferas (Tabela 5). Observou-se menor crescimento das colônias de $C$. cladosporioides que foram submetidos à atmosfera controlada a $25^{\circ} \mathrm{C}$ (Tabela 5). O efeito deletério da restrição atmosférica (já mencionada para C. gloeosporioides) sobre o crescimento das colônias de C. cladosporioides pode, assim, ser verificado. Isto significa que, em temperatura mais elevada, a atmosfera controlada mostrou-se efetiva para redução do desenvolvimento fúngico in vitro.

Pelas Tabelas 2 e 4, pode-se sugerir efeito fungistático, e não fungicida, da atmosfera controlada, pois houve crescimento após os períodos de armazenamento (7 e 14 dias). Não se pode inferir muito sobre esta questão, pois, nestas tabelas, são apresentados os efeitos gerais de temperatura e de data de avaliação, ou melhor, as médias das duas condições atmosféricas.

Fonseca et al. (2004) verificaram a incidência de algumas doenças em mamão, como: antracnose, podridão peduncular e mancha chocolate, durante o armazenamento sob atmosfera controlada contendo $6 \%$ de $\mathrm{CO}_{2}$ à temperatura de $10^{\circ} \mathrm{C}$. Estes autores sugeriram que a elevação dos níveis de $\mathrm{CO}_{2}$ pode ter promovido injúria fisiológica na casca dos frutos e a conseqüente manifestação das doenças citadas. Fonseca (2002) não verificou diferença na ocorrência de doenças em mamão produzido durante o inverno e armazenado sob atmosfera controlada contendo $3 \%$ de $\mathrm{CO}_{2}$ e atmosfera normal, o que pode ser indício de que o frio estacional pode ter condicionado os frutos à tolerância ao frio.

Tian et al. (2005) verificaram o efeito benéfico da atmosfera controlada $(5 \% \mathrm{O} 2$ e 5\% CO2) em relação à atmosfera modificada e atmosfera normal, no armazenamento a $3^{\circ} \mathrm{C}$, o que contribuiu para a redução da deterioração e descoloração em lichia (Litchi chinensis Sonn.) cv. Heiye, uma fruta de clima subtropical. Babic \& Watada (1996) verificaram que a atmosfera controlada reduziu o crescimento microbiano em espinafre minimamente processado em até 100 vezes, desde que esta hortaliça estivesse armazenada até $5^{\circ} \mathrm{C}$ por, no máximo, 7 dias.

Embora a combinação entre atmosfera controlada, tratamento hidrotérmico $\left(63^{\circ} \mathrm{C}\right.$ por $12 \mathrm{~s}$ ) e controle biológico (com a levedura Pichia guilliermondii Wickerham) tenha reduzido a deterioração por Botrytis cinerea Pers.:Fr. em morango após 5 dias, a $5^{\circ} \mathrm{C}$, mais 2 dias a $20^{\circ} \mathrm{C}$ e após 14 dias a $5^{\circ} \mathrm{C}$ mais 2 dias a $20^{\circ} \mathrm{C}$, Wszelaki \& Mitcham (2003) não verificaram diferença significativa em relação ao uso de atmosfera controlada isoladamente. Desta forma, os autores concluíram que não houve controle superior ao tratamento comercial de $15 \% \mathrm{CO}_{2}$.

TABELA 1 - Resumo da análise de variância para o diâmetro das colônias de Colletotrichum gloeosporioides e Cladosporium cladosporioides.

\begin{tabular}{lcccc}
\hline Fonte de variação & G.L. & C. gloeosporioides & C. cladosporioides \\
\cline { 3 - 5 } & & Quadrado médio & Quadrado médio \\
\hline Atmosfera (ATM) & 1 & $431,99^{* *}$ & $589,97^{* *}$ \\
Temperatura (TEMP) & 1 & $16.698,22^{* *}$ & $1.302,09^{* *}$ \\
Data de avaliação (DATA) & 3 & & $4.564,96^{* *}$ & $1.042,00^{* *}$ \\
ATM x TEMP & 1 & $115,44^{*}$ & $256,71^{* *}$ \\
ATM x DATA & 3 & $5,44^{\text {n.s. }}$ & $18,52^{\text {n.s. }}$ \\
TEMP x DATA & 3 & $724,00^{* *}$ & $262,67^{* *}$ \\
\hline ATM x TEMP x DATA & 3 & $39,81^{\text {n.s. }}$ & $9,59^{\text {n.s. }}$ \\
\hline Resíduo & 64 & 22,49 & 9,03 \\
\hline C.V.\% & & $\mathbf{1 4 , 1 4 2}$ & $\mathbf{2 0 , 4 9 8}$ \\
\hline
\end{tabular}

** significativos a $1 \%$ de probabilidade; *significativo a $5 \%$ de probabilidade, ${ }^{\text {n.s. }}$ não-significativo

TABELA 2 - Diâmetros médios das colônias de Colletotrichum gloeosporioides (em mm) nas diferentes temperaturas, durante o armazenamento

\begin{tabular}{lcc|cc}
\hline Temperatura & \multicolumn{4}{c}{ Período total } \\
\cline { 2 - 5 } & $\begin{array}{c}\text { Período de armazenamento } \\
\text { (dias) }\end{array}$ & $\begin{array}{c}\text { Período adicional de 7 dias, a 25 } 5^{\circ} \mathrm{C} \text {, para ambos } \\
\text { os períodos de armazenamento (7 e 14 dias) }\end{array}$ \\
\cline { 2 - 5 } & 7 & 14 & $7+7$ & $14+7$ \\
\hline $10^{\circ} \mathrm{C}$ & $1,70 \mathrm{Bb}$ & $1,80 \mathrm{Bb}$ & $38,00 \mathrm{Ba}$ & $34,39 \mathrm{Ba}$ \\
$25^{\circ} \mathrm{C}$ & $37,05 \mathrm{Ad}$ & $43,25 \mathrm{Ac}$ & $63,85 \mathrm{Aa}$ & $48,25 \mathrm{Ab}$ \\
\hline
\end{tabular}

* Médias seguidas de uma mesma letra, maiúscula na coluna e minúscula na linha, não diferem entre si, pelo teste de Tukey, a 5\% de probabilidade. 
TABELA 3 - Diâmetros médios de crescimento de Colletotrichum gloeosporioides (em mm) nas diferentes atmosferas e temperaturas de armazenamento.

\begin{tabular}{|c|c|c|}
\hline \multirow[t]{2}{*}{ Temperatura } & \multicolumn{2}{|c|}{ Atmosfera } \\
\hline & Ambiente & Controlada \\
\hline $10^{\circ} \mathrm{C}$ & $20,09 \mathrm{Ba}$ & $17,85 \mathrm{Ba}$ \\
\hline $25^{\circ} \mathrm{C}$ & $51,62 \mathrm{Aa}$ & $44,57 \mathrm{Ab}$ \\
\hline
\end{tabular}

* Médias seguidas de uma mesma letra, maiúscula na coluna e minúscula na linha, não diferem entre si, pelo teste de Tukey, a 5\% de probabilidade.

TABELA 4 - Diâmetros médios de crescimento de Cladosporium cladosporioides (em mm) nas diferentes temperaturas, durante o armazenamento.

\begin{tabular}{lcc|cc}
\hline Temperatura & \multicolumn{3}{c}{ Período total } \\
\cline { 2 - 5 } & $\begin{array}{c}\text { Período de armazenamento } \\
\text { (dias) }\end{array}$ & $\begin{array}{c}\text { Período adicional de 7 dias, a 25 } 5^{\circ} \text { C, para ambos } \\
\text { os períodos de armazenamento (7 e 14 dias) }\end{array}$ \\
\cline { 2 - 5 } & 7 & 14 & $7+7$ & $14+7$ \\
\hline $10^{\circ} \mathrm{C}$ & $1,80 \mathrm{Bc}$ & $3,60 \mathrm{Bc}$ & $16,30 \mathrm{Bb}$ & $20,80 \mathrm{Aa}$ \\
$25^{\circ} \mathrm{C}$ & $12,33 \mathrm{Ac}$ & $16,55 \mathrm{Ab}$ & $27,80 \mathrm{Aa}$ & $18,10 \mathrm{Bb}$ \\
\hline
\end{tabular}

* Médias seguidas de uma mesma letra, maiúscula na coluna e minúscula na linha, não diferem entre si, pelo teste de Tukey, a 5\% de probabilidade.

TABELA 5 - Diâmetros médios de crescimento de Cladosporium cladosporioides (em mm) nas diferentes atmosferas e temperaturas de armazenamento.

\begin{tabular}{lcc}
\hline Temperatura & \multicolumn{3}{c}{ Atmosfera } \\
\cline { 2 - 3 } & Ambiente & Controlada \\
\hline $10^{\circ} \mathrm{C}$ & $11,55 \mathrm{Ba}$ & $9,70 \mathrm{Ba}$ \\
$25^{\circ} \mathrm{C}$ & $23,20 \mathrm{Aa}$ & $14,19 \mathrm{Ab}$ \\
\hline
\end{tabular}

* Médias seguidas de uma mesma letra, maiúscula na coluna e minúscula na linha, não diferem entre si, pelo teste de Tukey, a 5\% de probabilidade.

\section{CONCLUSÕES}

1) Foi verificada a redução do crescimento das colônias dos fungos Colletotrichum gloeosporioides e Cladosporium cladosporioides, no armazenamento a $25^{\circ} \mathrm{C}$, submetidas a atmosfera controlada. Tal efeito não foi significativo na temperatura usual de refrigeração $\left(10^{\circ} \mathrm{C}\right)$ para exportação do mamão pelos produtores brasileiros. Assim, o possível benefício da atmosfera controlada no controle de patógenos em pós-colheita do mamão in vitro, somente deverá ser visualizado em temperaturas de refrigeração acima de $10^{\circ}$ $\mathrm{C}$, que retardem o metabolismo do fruto e possibilitem que o controle da atmosfera exerça seu efeito fungistático.

2) Novos experimentos devem ser conduzidos para testar a eficiência da atmosfera controlada para os demais patógenos do mamão em pós-colheita, bem como a combinação desta tecnologia com temperaturas mais brandas de refrigeração, evitando-se um possível efeito sinergístico da temperatura e atmosfera controlada promevendo injúria por frio. Outro fator importante a ser estudado é a concentração de $\mathrm{CO}_{2}$ ideal para evitar injúria fisiológica.

\section{REFERÊNCIAS}

BABIC, I.; WATADA, A.E. Microbial population on fresh cut spinach leaves affected by controlled atmosphere. Postharvest Biology and Technology, Amsterdan, v.9, p.187-193, 1996.

FONSECA, M.J. DE O. Conservação pós-colheita de mamão (Carica papaya L.): análise das cultivares Sunrise Solo e Golden, sob controle de temperatura e da atmosfera. 2002. 177f. Tese (Doutorado). Centro de Ciências e Tecnologias Agropecuárias. Universidade Estadual do Norte Fluminense, Campos dos Goytacazes, Brasil, 2002
FONSECA, M.J.O.; LEAL, N.R.; CENCI, S.A. Padrão de ocorrência de doanças em mamão armazenado sob atmosfera controlada. Revista Brasileira de Fruticultura, Jaboticabal, v.26, n.3, p.547549, 2004.

LANA, M M; FINGER, F L. Atmosfera modificada e controlada: aplicação na conservação de produtos hortícolas. Brasília: Embrapa Comunicação para Transferência de Tecnologia/ Embrapa Hortaliças, 2000.

NERY-SILVA, F.A . Aspectos patogênicos e controle químico da podridão peduncular de mamão (Carica papaya $\mathbf{L}$.). 1999. $62 \mathrm{f}$. Dissertação - (Mestre em Agronomia). Universidade Federal de Lavras, Lavras, 1999.

PERES, A.P.; SILVA-MANN, R.; VIEIRA, M.G.G.C.; MACHADO, J.C. Variabilidade morfocultural e genética de fungos associados à podridão peduncular do mamão. Ciências Agrotécnicas, Lavras, v.27, n.5, p.1053-1062, set./out. 2003

SNOWDON, AL. A Colour Atlas of post-harvest: diseases \& disorders of fruits \& vegetables. London: Wolfe Scientific, 1991. v.1.

TIAN S.P., LI; B.Q.; XU, Y. Effects of $\mathrm{O}_{2}$ and $\mathrm{CO}_{2}$ concentrations on physiology and quality of litchi fruit on storage. Food Chemistry, Kidlington, v.91, p.659-663, 2005

WSZELAKI, A.L.; MITCHAM, E.J. Effect of combinations of hot water dips, biological control and controlled atmospheres for control of gray mold on harvested strawberries. Postharvest Biology and Technology, Amsterdan, v.27, p.255-264, 2003.

WSZELAKI, A.L.; MITCHAM, E.J. Effects of superatmospheric oxygen on strawberry fruit quality and decay. Postharvest Biology and Technology, Amsterdan, v.20, p.125-133, 2000

YACKEL, W.C.; NELSON, A.I.; WEI, L.S.; STEINBERG, M.P. Effect of controlled atmophere on growth of mold on synthetic media and fruit. Applied Microbiology, Basel, v.22, n.4, p.513-516, 1971. 